\title{
Is education the best contraception: the case of teenage pregnancy in England?
}

\author{
Sourafel Girma \\ School of Economics \\ Sir Clive Granger Building \\ Nottingham University \\ University Park \\ Nottingham \\ NG7 2RD \\ United Kingdom \\ Tel: + 00441159515482 \\ Email: Sourafel.Girma@nottingham.ac.uk \\ and \\ David Paton* \\ Nottingham University Business School \\ Jubilee Campus \\ Wollaton Road \\ Nottingham \\ NG8 1BB \\ United Kingdom \\ Tel: + 00441158466601 \\ Email: David.Paton@nottingham.ac.uk
}

\begin{abstract}
This paper examines potential explanations for recent declines in teenage pregnancy in England. We estimate panel data models of teenage conception, birth and abortion rates from regions in England. Although point estimates are consistent with the promotion of long acting reversible contraception (LARC) having a negative impact on teenage pregnancy rates, the effects are generally small and statistically insignificant. In contrast, improvements in educational achievement and, to a lesser extent, increases in the non-white proportion of the population are associated with large and statistically significant reductions in teenage pregnancy.
\end{abstract}

Keywords: England, fixed effects, long acting reversible contraception, teen pregnancy, abortion.

JEL Classifications: C21, I18, J13. 


\section{Is education the best contraception: the case of teenage pregnancy in England?}

\section{Introduction and Background}

In recent years, teenage pregnancy rates in England have decreased significantly and a number of potential explanations have been proposed. The first and most obvious is increased promotion of long acting reversible forms of contraception (LARCs). LARCs have the advantage over other birth control methods in that, once administered, their efficacy is no longer reliant on the user (Winner et al, 2012). However, the effect of policies to promote LARC will depend not only on the effectiveness of LARCs for individuals, but also on whether the promotion creates unintended consequences amongst the population. For example, economists such as Ackerlof, Yellen and Katz (1996) have argued that access to more efficient birth control methods may lower the effective costs of risky sexual behaviour and, hence, increase unintended pregnancy rates.

Another possible explanation for the downward trend in teenage pregnancy is the significant improvement in measures of school-level outcomes in England, particularly in areas characterised by high levels of deprivation. An increased proportion of young people remaining in education after the statutory school leaving age is likely to increase the opportunity cost of early pregnancy and, hence, may contribute to lower teenage pregnancy rates. In addition, England has experienced high levels of immigration among groups that may be at a lower risk of very early pregnancy (for example due to relatively high religious observance), whilst there has also been a notable decrease in alcohol consumption amongst young people, a factor that is known to be highly correlated with early pregnancy.

In this paper, we use panel data from nearly 100 areas in England to estimate the impact of some of these factors in explaining changes in conceptions, births, and abortions amongst teenagers. In the next section of the paper, we summarise the key findings from 
previous research on the determinants of teenage pregnancy. In section 3, we explain recent trends in teenage pregnancy in England and associated policy responses. In section 4, we introduce our methodology and data, while in the final two sections of the paper; we discuss our econometric results and draw out some implications for future research.

\section{Existing Evidence on the Determinants of Teenage Pregnancy}

There is a large body of literature examining the determinants of adolescent pregnancy and abortion rates. Some form of consensus exists that indicate socio-economic and demographic factors are important in explaining differences in rates between areas and over time. In particular, high rates of early pregnancy have been found to be correlated with factors such as poverty, deprivation, low educational achievements, unstable family structures, religion and ethnicity (Adamczyk and Felson, 2008; Akers, 2011; Blackman, 2013; Evans et al, 1992; Girma and Paton, 2011; Paton, 2002).

The evidence on more direct determinants such as sex and relationship education (SRE) and contraception is more nuanced. There is little doubt that decreases in adolescent pregnancy rates are associated with both reductions in sexual activity and increases in contraceptive use (see, for example, Santelli et al, 2007 and Mohn et al, 2003). However, the effect of policy interventions in these areas has been harder to establish. For example, although Wilkinson et al (2006) found expenditure on the 1999 English Teenage Pregnancy Strategy was associated with lower under-18 conception rates, they also found specific measures such as high quality SRE or contraceptive access not to be associated with reductions in conception rates. In a review article, Imamura, Tucker, Hannaford et al (2007) conclude "evidence that access to services in itself is a protective factor remains inconsistent" (p.630). More recently, Blackman (2013) found that, “dedicated planning to tackle high teenage conception rates appears to make things worse" (p.69). 
Looking specifically at school-based sex and relationships education (SRE), Oettinger (1999) provides evidence that, amongst some sub-groups, teenagers who were exposed to school-based SRE experienced slightly higher pregnancy rates than those who were not exposed. In contrast, Kohler et al. (2008) found SRE to be associated with lower self-reported pregnancy rates amongst teenagers. Other researchers conclude that SRE has little or no significant effect on adolescent fertility (DiCenso et al, 2002; Sabia, 2006; Stephenson et al., 2008; Cavazos-Rehg et al, 2012).

The evidence on improving access to birth control is similarly ambiguous. A range of population-level studies and randomised controlled trials (RCTs) from both the USA and the UK (e.g. Arcidiacono et al, 2012; Paton, 2002; DiCenso et al., 2002; Evans et al, 1992) have found little evidence that better access to birth control services reduces teenage pregnancy rates, particularly amongst younger age groups, although there is some evidence that services are associated with fewer adolescent births (Kearney and Levine, 2009) but more abortions (Wilkinson et al., 2006). A number of studies (Durrance, 2012; Girma and Paton, 2011, 2006; Raymond et al, 2007) have focused specifically on access to emergency birth control (the 'morning after pill') but these have been unable to find any effect in terms of reductions in unwanted pregnancy or abortion. Much of this work has emphasised how some policy interventions aimed at mitigating the effects of risky sexual activity have the potential to increase the aggregate level of risky behaviour amongst adolescents (see also Klick and Stratmann, 2008).

Evidence regarding the impact of LARC promotion to teenagers is much more limited. Peipert et al (2012) examined the effect of promoting LARCs amongst adolescents in St. Louis, Missouri and found a subsequently low rate of teen births relative to the general population. However, their sample comprised teens who wished to avoid pregnancy. Given that at least some teens in the general population will be actively seeking to give birth, it is 
difficult to make inferences from this study about the impact of LARC promotion at the population level. Indeed to date, no empirical study has examined the extent to which promotion of LARCs leads to reductions in unwanted pregnancy rates amongst adolescents. This represents a significant gap in our knowledge.

\section{Teen Pregnancy in England}

Teen pregnancy rates in England are amongst the highest in the western world. Towards the end of 1999, the Government announced a major Teenage Pregnancy Strategy with the objective of achieving significant reductions in under-18 and under-16 pregnancy rates by the year 2010. Figure 1 illustrates under-18 conception and abortion rates from 1994 -2012 along with the Strategy expenditure. Up until 2008, there was little evidence of a strong impact of the Strategy on either conception or abortion. From 2008, however, pregnancy rates started to decrease significantly and the downward trend has continued even after Strategy ended in 2010.

Throughout this period, a key policy focus has been to increase access to family planning services for young people. In recent years there has been a particular focus on LARCs. In 2005, the National Institute for Health and Care Excellence (NICE) published new guidelines encouraging the promotion of LARCs. This was followed up in 2008 by a further directive from the Department of Health aimed at encouraging local areas to promote the use of LARCs amongst young people (Hairon 2008). As a result of these initiatives, the relative take-up of these forms of birth control amongst teens has increased steadily. For example, in 2004 which is the earliest year family planning data are reported for under-18s, just $6 \%$ of under-18 year olds accessing family planning clinics in England were provided with LARC compared to $34 \%$ being given condoms. As shown in Figure 2, by 2012, the 
percentage using LARCs had more than doubled, whilst the percentage provided with condoms had decreased by over $10 \%$.

Looking at the other potential explanatory factors for the decrease in teen pregnancies, there has been a significant increase in the proportion of 16 and 17 year olds staying in full-time education (see Figure 2), along with associated improvements in educational outcomes. Given the consensus regarding the role of education in delaying pregnancy, it is plausible that this has played a role in lower teenage pregnancy rates. There has also been significant demographic change in many areas. For example, Figure 2 illustrates that the non-white proportion of the population aged 15-17 has increased nationwide from just over $11 \%$ in 2004 to more than $16 \%$ in 2012. To the extent that recent immigrants are from communities that are at lower risk of very early pregnancy (for example due to relatively high religious observance), this trend may also have contributed to lower teenage pregnancy rates. Indeed, Blackman (2013) notes that decreases in teenage pregnancy rates in England have been most marked in areas with high levels of black and ethnic minority populations. Additionally, if such groups have relatively high educational aspirations, any effect on teenage pregnancy rates, may be felt indirectly through better educational outcomes.

The final factor is a more general decrease in risky behaviour which has been observed amongst teenagers. Annual surveys carried out on teenagers in England suggest that drug, alcohol use and smoking have all decreased significantly over the past 10 years (Fuller, 2013). Figure 2 shows the percentage of 11-15 year olds in these surveys who report using drinking alcohol within the past week had dropped from 23\% in 2004 to just $10 \%$ in 2012. Given the noted correlation between alcohol and early pregnancy, this appears to be another possible explanatory factor for the recent reduction in pregnancy rates. Rashad and Kaestner (2004) argue that, although alcohol use is strongly correlated with early sexual activity and 
pregnancy, research to date has failed to confirm that there is a causal effect. Rather,. There may exist other social trends which are at the root cause of the general decrease in teen risky behaviour. Indeed, it is notable that the rise in importance of online social networking has occurred over a very similar time period and it is not implausible that virtual social interactions have, to some extent, crowded out physical interactions.

Given that many of these changes have happened over the same period, it is hard to infer from national data which, if any, has played a causal role. The fact that much of the expenditure on the English Teenage Pregnancy Strategy was devolved to the local level, with each area having the discretion to set their own priorities, has meant that local data are likely to be helpful in disentangling at least some of the effects. For example, there has been considerable variation (both over time and across areas) in the promotion of LARCs and in achieving improvements in educational outcomes and this variation should aid in the identification process.

We now go on to explain in more detail the available data and methodological approach we used to disentangle different explanations of the decrease in teenage pregnancy.

\section{Data and Methods}

\section{Data}

Our unit of analysis is higher tier local authorities in England. This allows us to use data from publicly funded family planning clinics in each area. In some cases, these data are only available (at least on a consistent basis over time) at an aggregate level for several local authorities combined. In these cases, we combine two or more local authorities leading to a sample of 97 distinct areas. We have annual data available from 2004 until 2012. Allowing for a few missing observations, our data set includes 872 observation points. 
Pregnancy data in England is of high quality relative to many other countries. There are legal requirements for the reporting of live births and abortions. The Office of National Statistics (ONS) provides estimates of the time of conception in each case in order to generate annual conception rates for each local authority in the country by age at conception. The ONS also break down the data into conceptions ending in abortion and those ending in live births. Our main unit of observation is under-18s as this was the key target group for the English Teenage Pregnancy Strategy. We also estimate separate models for under-16s (16 being age of consent in England) and for 16-17 year olds. For under-16s we use the female population aged 13-15 as the denominator.

To measure promotion of LARCs, we use the two indicators suggested by Public Health England in their Sexual Health Balanced Scorecard (see www.apho.org.uk/default.aspx?QN=SBS_PAGE02). The first is the uptake of LARCs amongst female users of community contraception clinics as a proportion of those using any birth control methods, including LARCs $(L A R C)$. The second is the rate of LARC prescribed by general practitioners (GPs) per thousand population (GPLARC). These indicators reflect the two main sources (community clinics and GPs) from which LARCs are available to adolescents.

Here, we focus primarily on the clinic-based indicator. There are several reasons for this decision. In the first place, the clinic data are reported for under-18 year olds (and also for under-16 and 16-17 year olds) whereas the GP data are only reported for all age groups combined. Also, there is survey evidence that indicates adolescents are relatively more likely than adults to obtain birth control from clinics (especially those aimed specifically at young people) than from GPs (Lader, 2008). Further, the GP data series only goes back to 2008, whereas the clinic level data is available from 2004. More fundamentally, as the clinic indicator measures the take-up of LARCs relative to other forms of birth control (primarily 
condoms and the pill); it will more closely reflect the promotion of LARC. An indicator based on the rate of take-up per population will not only reflect promotion but also other supply-side effects (e.g. a general cut back or expansion of family planning clinics in an area) that are not specific to LARCs as well as demand-side effects. For example, an independent increase in sexual activity (or an increase in the desire to avoid pregnancy) may lead to a higher uptake of all family planning methods, not just LARCs, that is unrelated to any policy to promote its use. That said, we do report results including the GP measures for the time period in which these data are available. For comparison, we also report estimates using the rate of clinic-based LARC take-up per population.

The clinic LARC data are published at primary care trust (PCT) level by the Department of Health (DoH) and are then mapped to local authority level. Birth control methods classified as LARC include IUDs, implants and birth control injections. A potential complication is that, in some cases, young people may obtain LARCs from a clinic in an area different to their authority of residence. To control for this, we also include the average of the LARC measure across each of the adjoining local authorities (LARC neighbour). We also conduct a specification check in which we exclude all local authorities in London, a region in which cross-border travel is especially common. A particular issue here is the case of Brook Advisory Centres. Brook is a significant provider of birth control services to young people. Although Brook is included in the community clinic data, the returns for London Brook are not broken down by the different boroughs. We allocate data from Brook to London boroughs in proportion to the relevant population.

In addition to our measures of LARC promotion, we include a dummy variable to indicate whether the area has a scheme providing emergency birth control at pharmacies free of charge to young people (Pharmacy). For the early years of our sample, we also control for access to birth control more generally by including the rate of specialist young people's 
family planning clinics in each area (Clinic). There are no suitable data which measure local changes in SRE provision over time. Hence, we rely on year- and area-fixed effects to capture this and other, unobservable factors for which annual data are unavailable.

A related issue is 'policy endogeneity' in which efforts to promote LARC are correlated with current or pre-existing trends in conception rates. In such an event, year and area fixed effects may not provide sufficient controls. For this reason we also report models with area-specific time trends. The downside of this approach is that it places very high demands on the data when there may be insufficient residual variation to identify effects of particular variables. We report a further specification in which we include lagged changes in conception rates. This variable (Pre-trend) is defined as the three-year moving average of lagged growth rates in teen conceptions where the most recent period (t-1) is given a weight of $1 / 2$ with periods $t-2$ and $t-3$ having weights of $1 / 3$ and $1 / 6$ respectively.

To measure educational outcomes, we include the three-year running average of the percentage of school pupils achieving five or more GCSE qualifications at grade C or above $(G C S E)$. This is one of the main indicators of performance at the standard school leaving age in England. Our measure of ethnicity is the proportion of the population of relevant age that are non-white (Non-white pop). As census-based data on race or ethnicity are not available on any consistent basis, we construct this measure using data published by the Department for Education for pupils in the final year of compulsory schooling. We also attempt to measure the impact of alcohol use amongst teens by including data published by Public Health England on the rate of hospital admissions by under-18s in each local authority (Alcohol), although these data are only available for the later years of our sample.

Finally, we include two other socio-economic variables: annual proportion of children of each age group in local authority care (Care) and the unemployment rate for females aged under 20 (Unem). Children placed in care are known to be at an enhanced risk of adverse 
outcomes in a range of areas including low educational attainment, substance abuse, early sexual activity and teenage pregnancy (Social Exclusion Unit, 1999). A high youth unemployment rate implies fewer workplace opportunities and, consequently, a lower opportunity cost of early pregnancy. As a result, we would expect both variables to be positively associated with teenage conception rates.

\section{Statistical methods}

In this section, we describe the empirical approach to identify the effects of LARC on teenage conception rates and related outcomes (i.e. abortion and birth rates). Our basic approach is to test whether those areas of England which have promoted LARCs most heavily have experienced decreases in teenage pregnancy relative to the national average. We specify the following panel data model of the determinants of conception with area firmspecific heterogeneity and time effects:

$$
\operatorname{CON}_{i t}=\beta_{0}+\beta_{1} X_{i t}+f_{i}+d_{t}+\varepsilon_{i t}
$$

where $i$ and $t$ index local authority areas and time periods respectively. The dependent variable $C O N$ denotes the number of conceptions ending in maternities or abortion to the relevant age group resident in each local authority per 1000 women. In our baseline estimation we consider conception rates for under-18 year of age. This will subsequently be divided into conception rates by under 16's and 16 and 17 year olds. $X$ is a vector of regressors hypothesised to impact on our dependent variable as discussed in the previous subsection. On the other hand, $f$ denotes time-invariant area-specific heterogeneity; $d$ is a vector of year dummies and $\varepsilon$ is a random error term which is allowed to exhibit heteroscedasticity as well serial correlation by clustering on local authorities. In all cases we use (female) population weighted regressions. 


\section{Panel Data Estimates of Teenage Pregnancy}

\section{Main Results}

We report some descriptive statistics in Table 1, including summaries of the crosssectional (between) and time-series (within) variation of each of our key variables. Recalling that the fixed-effects models rely on time-series variation to identify the impact of each variable, note that most of the time-varying variables display a considerable amount of ‘within' variation.

The baseline estimates of the models for under-18's are reported in Table 2. The national data reported in Figure 1 suggests a clear structural break in teenage pregnancy conceptions from 2008. Given this, it may be that the effect of one or more of our independent variables on conceptions changes around this point, in which case pooling both time periods, could obscure true effects. For this reason, we report results for the whole time period (2004-2012) and also separately for 2004-2007 and 2008-2012. All the models include year- and area- fixed effects along with the family planning, education, race, and socioeconomic variables.

For the whole time period, there is very little evidence that LARCs are associated with fewer teenage pregnancies. Although the coefficients on the clinic LARC variable are negative (implying that promotion of LARCs leads to fewer pregnancies), none are statistically significant at the 5\% level and they imply fairly small effects. For example, the coefficient for conceptions using the whole time period (-0.074) implies that an increase in the proportion using LARCs of $10 \%$ from its mean of 9.639 would reduce the mean value of conceptions for this group by less than $0.2 \%$. The magnitude of the coefficient is a little larger in the early time period, whilst, for the most recent period, the coefficient is actually positive though of negligible magnitude. The coefficients on LARC promotion in 
neighbouring areas and on the GP LARC measure (reported for the later period only) are also small in magnitude, vary in direction, and rarely approach statistical significance.

Coefficients on the other birth control variables are generally negative but never close to statistical significance, consistent with previous work (Girma and Paton, 2011; Durrance, 2012). In contrast, our indicator of educational performance is significantly associated with lower teenage pregnancies and the estimated effects are large. For example, a $10 \%$ increase in GCSE implies a reduction in the teenage conception rate of about $8 \%$. Given that, at a national level, the numbers achieving five good GCSEs have increased by about $50 \%$ since 2004, this factor alone has the potential to explain a large proportion of the recent decrease in teenage conceptions. The effect is larger for births than abortions, a result which is consistent with expectations: to the extent that giving birth is an impediment to continuing with studies to a higher level, improved educational achievement should increase the opportunity cost of giving birth, but not necessarily of having an abortion, at a young age. Finally, the effect of education is strongest for the later time period when pregnancy rates were falling fastest.

Increases in the non-white proportion in the population are also associated with significantly fewer teenage pregnancies. In terms of the magnitude of the effect, a $10 \%$ increase in the non-white population is associated with a decrease in the under-18 conception rate of just under $2 \%$. The effect of this variable appears to be more important in the earlier time period. However there is a fairly high degree of collinearity between Non-white and GCSE. When the latter is excluded, the coefficient on Non-white is significant even in the later time period. An obvious explanation is that the non-white proportion in the population influences teenage pregnancies through the relatively high value new immigrant groups place on education. A further issue may be the significant increase in new immigrants amongst the white population in recent years. Unfortunately data availability does not allow us to explore the latter issue satisfactorily. 
The coefficient on our measure of alcohol (available for the later period only) is positive but never close to statistical significance. We also find a positive association between female unemployment and conception rates, although the effect appears to be strongest in the earlier time period. Finally, the rate of children in care is positively associated with conception rates, but only significantly so for the later time period.

\section{Specification Checks}

We now go on to report a number of alternative specifications to explore the robustness of these findings. In Table 3, we report results estimated separately for older (1617's) and younger (under-16's) age groups using the full time period. The results in both cases are similar to those for under-18s. One exception is that the coefficients on non-white are not statistically significant (though still negative) for the under-16 group.

In Table 4, we report several other specifications again using the full time period. First, as a further check for the effect of cross-border travel, we exclude any area within London (where the problem of teenagers in one area accessing family planning services in an adjacent area is likely to be most pronounced). In fact, the results are very similar with and without London. We are still unable to identify any significant impact of LARC on teenage pregnancy rates, whilst we continue to find strong links with educational performance and the non-white population.

The next two specifications attempt to control for policy endogeneity. We first add in area-specific time trends to the baseline model. In this case, the point estimate of the coefficient on LARCs for conceptions is a little lower than in the baseline models. However, the coefficient for births is now negative and statistically significant at the $5 \%$ level. In an alternative approach to the issue, we include lagged growth in conception rates (as described above). This variable is strongly significant but its inclusion does not materially change the estimated effect of the other variables. 
The next experiment is to estimate the baseline model using the take-up of LARCs relative to the total population (rather than relative to women being given contraception at family planning clinics). In contrast to the other models, the rate of LARC take-up is associated with significant decreases in teenage conceptions and births (though not abortions). Even here, the magnitude of the estimated effect is insufficient to explain much of the observed decreased in teenage pregnancies over the period. For example, a $10 \%$ increase in the rate of LARC use at community clinics is associated with a reduction in the under-18 conception rate of about $0.3 \%$.

In Table 5, we repeat the robustness checks from Table 4, but estimated separately for the early and later time periods. For reasons of space, we only include the estimates for conceptions. The results are generally consistent with those reported in the baseline models in Table 2.

In the final table of results, we explore whether any effect of LARC promotion is moderated by our measures of educations outcomes and non-white population. We do this by supplementing our baseline model with two interaction terms. We find some evidence of a moderating effect for GCSE results, but not for the non-white population. Specifically, the main effect for LARCs is still negative but now somewhat larger in magnitude than previously. In contrast, the coefficient on the interaction term with GCSE results is positive and statistically significant. The interpretation is that, at the lower levels of educational outcomes, promotion of LARCs has a negative impact (i.e. teenage conceptions decrease) but a positive impact when educational outcomes are better. However, the magnitudes of the effects are still small and only marginal statistically significant. Further, when we split the sample up, the effects are larger in the earlier time period than in the more recent period when conception rates were falling fastest.

\section{Discussion and Conclusions}


Decreasing teenage pregnancy rates in England since 2008 have coincided with trends in several potential explanatory factors. Most obviously, family planning policy in England has shifted towards heavy promotion of long acting reversible methods (LARCs) which are likely to have much lower failure rates than the pill and condoms. At the same time, we have seen notable improvements in indicators of educational outcomes, significant demographic change in many areas and lower rates of alcohol use amongst young people. In this paper, we have sought to identify the relative importance of these trends in explaining changes in teenage conception rates using panel data from local areas in England.

Although we find that promotion of LARCs as measured by official indicators are generally associated with lower teenage pregnancy rates, the point estimates are small in magnitude and of marginal statistical significance. Further, any effects appear to be even smaller in the period since 2008 when conception rates have fallen fastest. We find some evidence that promotion of LARCs has more of an effect on teenage births than abortions and in areas with poorest educational outcomes. Even in these cases, the magnitude of the effects is too small and uncertain to satisfactorily explain much of the overall decline in teenage pregnancy. As this is the first study directly to test the impact of the promotion of LARCs on adolescent pregnancy, it will be important to see whether this result is replicated in other settings and with other research designs. However, the results in this paper are consistent with the literature on emergency birth control (EBC) which similarly conclude that access to EBC has, at best, a very small impact on unwanted pregnancy or abortions (Raymond et al, 2007; Girma and Paton, 2011; Durrance, 2012.).

In contrast, and consistent with previous work (Girma and Paton, 2011) we find strong evidence that educational performance is associated with lower pregnancy (and especially birth) rates. We also find that increases in the non-white population in an area are associated with lower teenage pregnancies. Although this latter result is not particularly 
robust to alternative specifications such as estimating the sample separately for an early and late time period, it is consistent with Blackman's (2013) observation that reductions in teenage pregnancy rates have been dominated by areas with high number of ethnic minority residents. Our measure of alcohol is not found to be significantly associated with adolescent conceptions.

Our results have several policy implications. Our finding that promotion of LARCs is unable to explain much if any of the recent reduction in teenage pregnancy somewhat undermines the heavy emphasis on these forms of birth control by policy makers in recent years. In contrast, our results provide justification for policy approaches which seek to tackle underage pregnancy by focusing on more general issues such as deprivation and opportunity, particularly in regard to education. Our finding that demographic change may have played a role in reducing teenage pregnancy rates casts an interesting perspective on the immigration debate. Although rapid immigration may be associated with short term problems relating to integration and social change, our results are consistent with recent waves of immigrants providing an impetus for improvements in long term measures of deprivation.

There are a number of caveats to our results. In the first place, our study design relies on fixed effects (both area and time) to identify the effect of each variable. It is possible that differential non-linear time effects across areas could obscure the true effect of, for example, LARCs. Further, although we would expect to identify any significant effect of promotion of LARCs in our approach, to be confident that there has been no impact, it would be useful to complement this research with approaches based on natural experiments or randomised controlled trials. We must also be careful before interpreting the relationship between educational outcomes and teenage pregnancy as directly causal. It is possible that there are other underlying factors which explain both why young people are less likely to leave school with no qualifications and are less likely to get pregnant early on. Indeed, the evidence that 
risk-taking amongst young people has reduced over a number of dimensions (smoking, drinking and drug-taking) is suggestive of a more systematic shift in teenage behaviour. Future research could usefully take on the challenge of attempting to identify the root cause of these changes. 


\section{References}

Adamczyk, A and Felson, J (2008), 'Fetal positions: unravelling the influence of religion on premarital pregnancy resolution'. Social Science Quarterly, 89 (1, March): 17-38.

Akerlof, G.A., J.L. Yellen, M.L. Katz (1996), 'An analysis of out-of-wedlock childbearing in the United States', Quarterly Journal of Economics, 111 (2, May): 277-317.

Akers, AY, MR Muhammad and G Corbie-Smith (2011), "When you got nothing to do, you do somebody": A community's perceptions of neighborhood effects on adolescent sexual behaviors', Social Science and Medicine, 72: 91-9.

Arcidiacono, P, A Khwaja and Ouyang, L. (2012), 'Habit persistence and teen sex: could increased access to contraception have unintended consequences for teen pregnancies?' Journal of Business and Economic Statistics, 30 (2, April): 312-325.

Blackman, T (2013) 'Exploring explanations for local reductions in teenage pregnancy rates in England: an approach using qualitative comparative analysis'. Social Policy and Society, 12 (1): 61-72.

Cavazos-Rehg, PA, MJ Krauss, EL Spitznagel et al. (2012), 'Associations between sexuality education in schools and adolescent birthrates: a state-level longitudinal model', Archives of Pediatric Adolescent Medicine, 166(2): 134-40.

DiCenso A, G Gordon, W Andrew and L Griffith (2002), 'Interventions to reduce unintended pregnancies among adolescents: systematic review of randomised controlled trials', British Medical Journal, 324(15, June): 1426-34.

Durrance, C (2012), 'The effects of increased access to emergency contraception on sexually transmitted disease and abortion rates', Economic Inquiry,

Evans WN, WE Oates and RM Schwab (1992), 'Measuring peer group effects: a study of teenage behavior', Journal of Political Economy, 100(5, Oct): 966-91.

Fuller, E (2013). Smoking, drinking and drug use among young people in England 2012, London: Health and Social Care Information Centre.

Girma, S and D Paton (2011), 'The impact of emergency birth control on teen pregnancy and STIs', Journal of Health Economics, 30(2, March): 373-380.

Girma S and D Paton (2006), 'Matching Estimates of the Impact of Over-the-Counter Emergency Birth Control on Teenage Pregnancy', Health Economics, 15(Sept): 102132.

Hairon, N (2008), 'Increasing use of long-acting reversible contraception', Nursing Times, 104 (42, October): 23-24. 
Imamura M, J Tucker, P Hannaford et al (2007), 'Factors associated with teenage pregnancy in the European Union countries: a systematic review', European Journal of Public Health, 17 (6, March): 630-6.

Kearney MS and PB Levine (2009), 'Subsidized contraception, fertility and sexual behavior', Review of Economics and Statistics, 9(1): 137-51.

Klick J and T Stratmann, (2008), 'Abortion access and risky sex among teens: parental involvement laws and sexually transmitted diseases', Journal of Law, Economics and Organization, 24 (1, May), 2-21

Kohler PK, LE Manhart and WE Lafferty (2008), 'Abstinence-Only and Comprehensive Sex Education and the Initiation of Sexual Activity and Teen Pregnancy' Journal of Adolescent Health, 42: 344-51.

Lader, D (2009), Contraception and Sexual Health 2008/09, Omnibus Survey No. 41, London: Office for National Statistics.

Mohn JK, LR Tingle, R Finger (2003), 'An Analysis of the Causes of the Decline in Nonmarital Birth and Pregnancy Rates for Teens from 1991 to 1995', Adolescent and Family Health, 3: 39-47.

Oettinger GS (1999), 'The effects of sex education on teen sexual activity and teen pregnancy', Journal of Political Economy, 107(3): 606-44.

Paton, D (2002), 'The economics of abortion, family planning and underage conceptions', Journal of Health Economics, 21 (2, March): 27-45.

Peipert JF, T Madden, JE Allsworth and GM Secura (2012), 'Preventing unintended pregnancies by providing no-cost contraception', Obstetrics \& Gynecology, 120(6, Dec):1291-1297.

Rashad I, and R Kaestner (2004), 'Teenage sex, drugs and alcohol use: problems identifying the cause of risky behaviors', Journal of Health Economics 23: 493-503.

Raymond EG, J Trussell and CB Polis (2007). 'Population effect of increased access to emergency contraception pills: a systematic review', Obstetrics \& Gynecology, 109 (1, Jan), 181-188.

Sabia JJ (2006), 'Does sex education affect adolescent sexual behaviors and health?', Journal of Policy Analysis and Management, 25(4): 783-802.

Santelli JS, LD Lindberg, LB Finer and S Singh (2007), 'Explaining recent declines in adolescent pregnancy in the US: the contribution of abstinence and improved contraceptive use', American Journal of Public Health, 97(1, Jan): 150-6.

Social Exclusion Unit (1999), Teenage Pregnancies, London: HMSO CM4342.

Stephenson J., V. Strange, E. Allen, A. Copas, A. Johnson, C. Bonell, A. Babiker, A. Oakley et al (2008), 'The long-term effects of a peer-led sex education programme (RIPPLE): 
a cluster randomised trial in schools in England', PLoS Medicine, 5(11, Nov): 157990 .

Wilkinson P, R French, R Kane et al. (2006), 'Teenage conceptions, abortions and births in England: 19894-2003, and the national teenage pregnancy strategy' Lancet, 368(Nov): 1879-86.

Winner B, JW Peipert, Z Qiuhong et al. (2012), 'Effectiveness of long-acting reversible contraception', New England Journal of Medicine, 366: 1998-2007. 


\section{Figures}

Figure 1: Under-18 conceptions, abortion rates and Teenage Pregnancy Strategy (TPS) spend 1995-2012

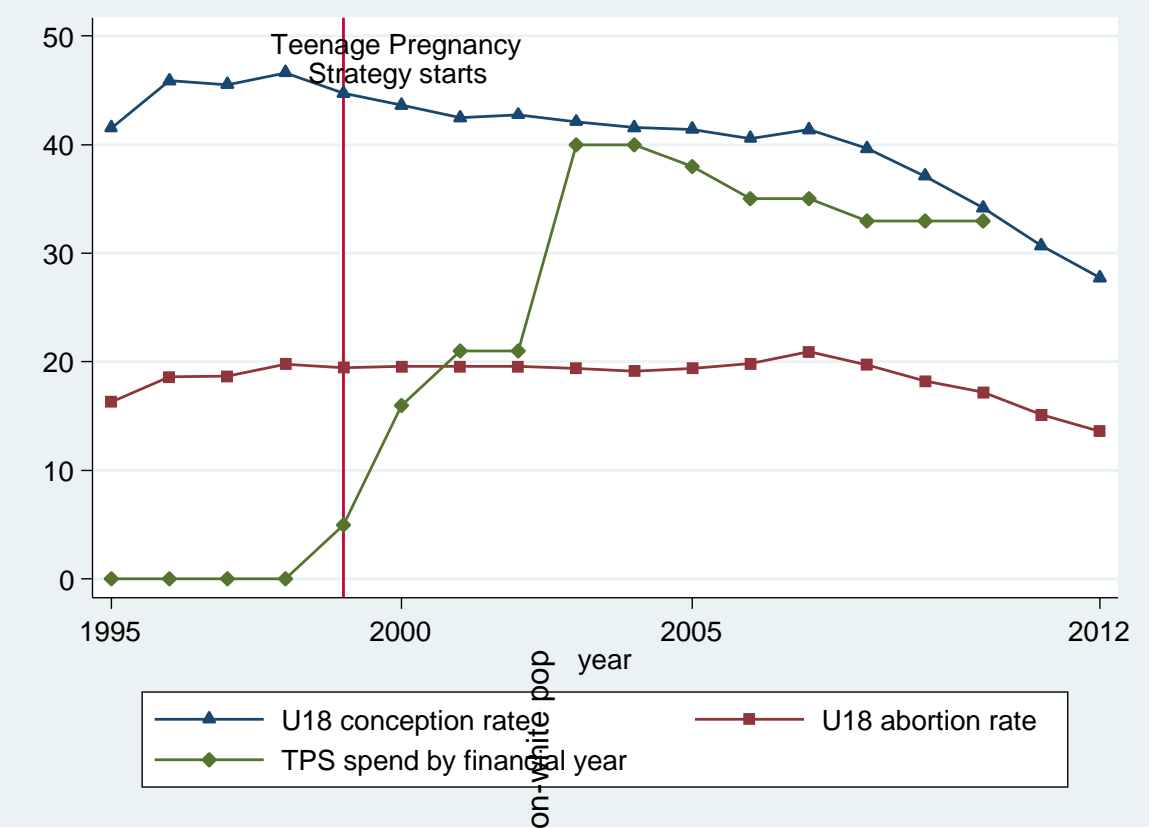

Note: Conception and abortion rates are based on estimated age at conception and are calculated per 1000

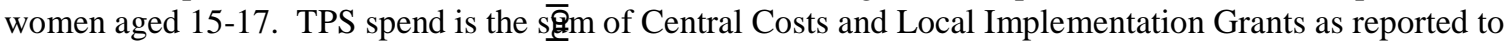
Parliament by the Secretary of State, so8irce:

www.publications.parliament.uk/p $/ \mathrm{d} / \mathrm{cm} 201011 / \mathrm{cmhansrd} / \mathrm{cm} 110317 / \mathrm{text} / 110317$ w0005.htm
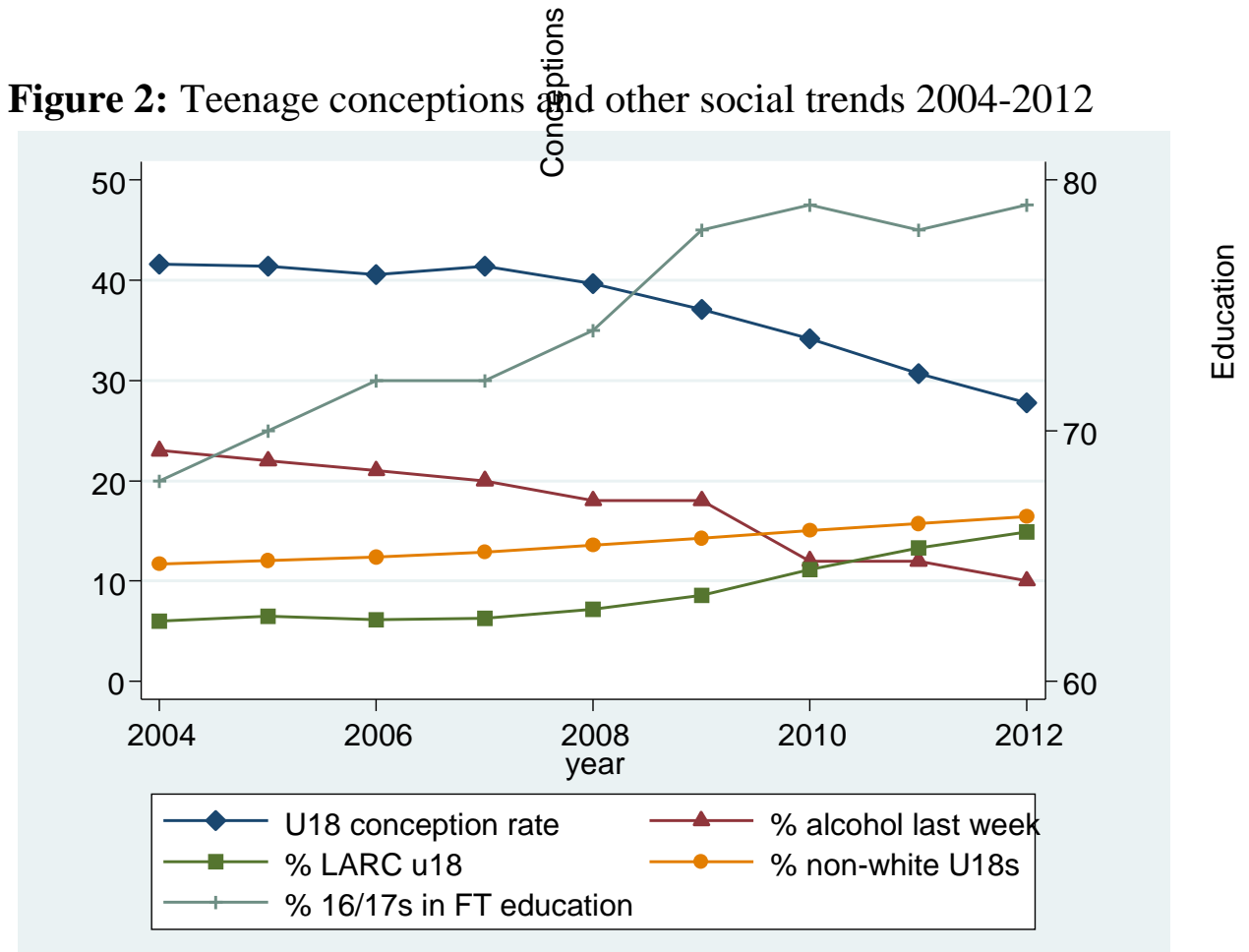

Notes: Conception rates are per 1000 women aged 15-17 as published by the ONS. \% LARCs is the percentage of first contacts with women at family planning clinics in England who are provided with a form of long acting reversible contraception, supplied to the authors by the Department of Health. \%16/17 in FT education and \% non-white are based on figures published by the Department for Education. \% alcohol figures are taken from Fuller (2013). 
1 Table 1: Summary statistics

\begin{tabular}{|l|c|c|c|c|c|}
\hline Variable & Mean & SD overall & SD within & SD between & $\begin{array}{c}\text { \% variation explained } \\
\text { by LA \& year effects }\end{array}$ \\
\hline Conceptions U18 & 38.69 & 11.82 & 6.500 & 9.920 & 0.887 \\
\hline Conceptions 16-17 & 46.79 & 14.53 & 8.402 & 11.91 & 0.872 \\
\hline Conceptions U16 & 7.444 & 2.563 & 1.489 & 2.101 & 0.763 \\
\hline Abortions U18 & 18.76 & 5.350 & 3.389 & 4.130 & 0.791 \\
\hline Abortions 16-17 & 21.41 & 6.380 & 4.228 & 4.797 & 0.768 \\
\hline Abortions U16 & 4.464 & 1.510 & 1.043 & 1.097 & 0.623 \\
\hline Births U18 & 19.93 & 8.171 & 3.874 & 7.234 & 0.901 \\
\hline Births 16-17 & 25.37 & 10.45 & 5.135 & 9.152 & 0.892 \\
\hline Births U16 & 2.980 & 1.445 & 0.822 & 1.155 & 0.736 \\
\hline LARC U18 & 9.639 & 6.506 & 5.054 & 4.114 & 0.664 \\
\hline LARC 16-17 & 10.71 & 6.633 & 5.009 & 4.367 & 0.663 \\
\hline LARC U16 & 7.748 & 6.887 & 5.607 & 4.015 & 0.607 \\
\hline LARC neighbour & 8.943 & 4.507 & 3.742 & 2.526 & 0.808 \\
\hline GPLARC & 46.43 & 16.49 & 5.964 & 15.44 & 0.972 \\
\hline LARC in rates U18 & 24.94 & 27.21 & 17.80 & 20.67 & 0.681 \\
\hline Pharmacy & 0.816 & 0.360 & 0.232 & 0.277 & 0.681 \\
\hline Clinic U18 & 44.33 & 37.05 & 17.65 & 32.71 & 0.777 \\
\hline GCSE U18/16-17 & 62.52 & 11.47 & 10.56 & 4.477 & 0.948 \\
\hline GCSE U16 & 66.19 & 12.37 & 11.66 & 4.162 & 0.950 \\
\hline Non-white pop U18 & 16.43 & 17.86 & 1.956 & 17.82 & 0.996 \\
\hline Non-white pop 16-17 & 16.17 & 17.77 & 1.921 & 17.73 & 0.996 \\
\hline Non-white pop U16 & 17.01 & 18.06 & 2.146 & 18.01 & 0.994 \\
\hline Alcohol U18 & 3.402 & 1.566 & 0.837 & 1.328 & 0.890 \\
\hline Unem & 1.347 & 0.549 & 0.268 & 0.482 & 0.872 \\
\hline Care U18 & 20.76 & 8.785 & 2.591 & 8.429 & 0.908 \\
\hline Care 16-17 & 10.43 & 6.235 & 2.381 & 5.786 & 0.873 \\
\hline Care U16 & 14.15 & 5.522 & 1.702 & 5.276 & 0.898 \\
\hline
\end{tabular}


Table 2: Determinants of under-18 conceptions, births \& abortions, 2004-2012

\begin{tabular}{|c|c|c|c|c|c|c|c|c|c|}
\hline & (1) & $\begin{array}{c}(2) \\
2004-2012\end{array}$ & (3) & $(4)$ & $\begin{array}{c}(5) \\
004-2007\end{array}$ & (6) & (7) & $\begin{array}{c}(8) \\
008-2012\end{array}$ & (9) \\
\hline & Conceptions & Abortions & Births & Conceptions & Abortions & Births & Conceptions & Abortions & Births \\
\hline LARC & $\begin{array}{l}-0.074 \\
(0.054)\end{array}$ & $\begin{array}{c}-0.020 \\
(0.028)\end{array}$ & $\begin{array}{l}-0.054^{*} \\
(0.031)\end{array}$ & $\begin{array}{l}-0.288 \\
(0.199)\end{array}$ & $\begin{array}{l}-0.139 \\
(0.103)\end{array}$ & $\begin{array}{l}-0.149 \\
(0.114)\end{array}$ & $\begin{array}{c}0.017 \\
(0.037)\end{array}$ & $\begin{array}{c}0.034 \\
(0.023)\end{array}$ & $\begin{array}{l}-0.017 \\
(0.027)\end{array}$ \\
\hline GPLARC & & & & & & & $\begin{array}{c}0.043 \\
(0.066)\end{array}$ & $\begin{array}{c}0.030 \\
(0.044)\end{array}$ & $\begin{array}{c}0.013 \\
(0.041)\end{array}$ \\
\hline GCSE & $\begin{array}{c}-0.511^{* * *} \\
(0.100)\end{array}$ & $\begin{array}{c}-0.156^{* * * *} \\
(0.056)\end{array}$ & $\begin{array}{c}-0.356^{* * *} \\
(0.062)\end{array}$ & $\begin{array}{l}-0.385^{* *} \\
(0.189)\end{array}$ & $\begin{array}{l}-0.031 \\
(0.126)\end{array}$ & $\begin{array}{c}-0.354^{* * *} \\
(0.116)\end{array}$ & $\begin{array}{c}-0.510^{* * * *} \\
(0.136)\end{array}$ & $\begin{array}{c}-0.278^{* * * *} \\
(0.079)\end{array}$ & $\begin{array}{c}-0.232^{* * *} \\
(0.079)\end{array}$ \\
\hline Non-white pop & $\begin{array}{l}-0.442^{* *} \\
(0.221)\end{array}$ & $\begin{array}{l}-0.189 \\
(0.124)\end{array}$ & $\begin{array}{l}-0.253 \\
(0.155)\end{array}$ & $\begin{array}{c}-1.271^{* * *} \\
(0.474)\end{array}$ & $\begin{array}{l}-0.460 \\
(0.338)\end{array}$ & $\begin{array}{c}-0.811^{* *} \\
(0.329)\end{array}$ & $\begin{array}{c}-0.096 \\
(0.258)\end{array}$ & $\begin{array}{c}0.007 \\
(0.170)\end{array}$ & $\begin{array}{l}-0.103 \\
(0.205)\end{array}$ \\
\hline LARC neighbour & $\begin{array}{l}-0.055 \\
(0.075)\end{array}$ & $\begin{array}{l}-0.016 \\
(0.039)\end{array}$ & $\begin{array}{l}-0.040 \\
(0.053)\end{array}$ & $\begin{array}{c}0.289 \\
(0.222)\end{array}$ & $\begin{array}{c}0.206 \\
(0.145)\end{array}$ & $\begin{array}{c}0.083 \\
(0.149)\end{array}$ & $\begin{array}{l}-0.128^{*} \\
(0.073)\end{array}$ & $\begin{array}{l}-0.072 \\
(0.046)\end{array}$ & $\begin{array}{c}-0.056 \\
(0.050)\end{array}$ \\
\hline Pharmacy & $\begin{array}{l}-0.372 \\
(0.900)\end{array}$ & $\begin{array}{l}-0.242 \\
(0.520)\end{array}$ & $\begin{array}{l}-0.130 \\
(0.602)\end{array}$ & $\begin{array}{l}-0.558 \\
(0.898)\end{array}$ & $\begin{array}{l}-0.553 \\
(0.618)\end{array}$ & $\begin{array}{l}-0.004 \\
(0.641)\end{array}$ & $\begin{array}{c}-0.734 \\
(1.630)\end{array}$ & $\begin{array}{c}0.067 \\
(0.905)\end{array}$ & $\begin{array}{l}-0.800 \\
(1.164)\end{array}$ \\
\hline Clinic & & & & $\begin{array}{l}-0.010 \\
(0.013)\end{array}$ & $\begin{array}{l}-0.006 \\
(0.009)\end{array}$ & $\begin{array}{l}-0.004 \\
(0.008)\end{array}$ & & & \\
\hline Unem & $\begin{array}{l}4.398^{* * *} \\
(1.533)\end{array}$ & $\begin{array}{l}3.450^{* * *} \\
(1.029)\end{array}$ & $\begin{array}{c}0.948 \\
(0.664)\end{array}$ & $\begin{array}{c}2.532 \\
(1.557)\end{array}$ & $\begin{array}{l}2.258^{*} \\
(1.265)\end{array}$ & $\begin{array}{c}0.274 \\
(0.985)\end{array}$ & $\begin{array}{c}-1.062 \\
(1.430)\end{array}$ & $\begin{array}{l}-0.580 \\
(1.001)\end{array}$ & $\begin{array}{c}-0.482 \\
(0.758)\end{array}$ \\
\hline Care & $\begin{array}{c}0.059 \\
(0.097)\end{array}$ & $\begin{array}{c}0.072 \\
(0.068)\end{array}$ & $\begin{array}{l}-0.013 \\
(0.049)\end{array}$ & $\begin{array}{l}-0.172 \\
(0.131)\end{array}$ & $\begin{array}{l}-0.091 \\
(0.102)\end{array}$ & $\begin{array}{l}-0.081 \\
(0.087)\end{array}$ & $\begin{array}{l}0.246^{* *} \\
(0.102)\end{array}$ & $\begin{array}{l}0.164^{* * *} \\
(0.056)\end{array}$ & $\begin{array}{c}0.083 \\
(0.063)\end{array}$ \\
\hline Alcohol & & & & & & & $\begin{array}{c}0.184 \\
(0.527) \\
\end{array}$ & $\begin{array}{c}-0.011 \\
(0.328) \\
\end{array}$ & $\begin{array}{c}0.195 \\
(0.338) \\
\end{array}$ \\
\hline $\mathbf{N}$ & 872 & 872 & 872 & 388 & 388 & 388 & 484 & 484 & 484 \\
\hline Adjusted $\mathbf{R}^{2}$ & 0.915 & 0.841 & 0.921 & 0.936 & 0.877 & 0.941 & 0.934 & 0.861 & 0.934 \\
\hline Mean Dep Vble & 38.69 & 18.76 & 19.93 & 43.24 & 20.66 & 22.58 & 35.04 & 17.23 & 17.80 \\
\hline
\end{tabular}

$5 \quad$ Notes

(i) ${ }^{*} p<0.10,{ }^{* *} p<0.05,{ }^{* * *} p<0.01$

(ii) All models include year and area fixed effects

(iii) Estimates are weighted by the relevant population in each area.

(iv) Standard errors are clustered on local authorities.

(v) Dependent variables are in rates per thousand women aged 15-17. 
Table 3: Robustness checks 1- Conceptions - older and younger teens, 2004-2012

\begin{tabular}{|c|c|c|c|c|c|c|}
\hline & \multirow{2}{*}{\multicolumn{3}{|c|}{$\begin{array}{c}(2) \\
16 \text { and } 17 \text { years old }\end{array}$}} & \multirow{3}{*}{$\begin{array}{c}(4) \\
\text { 2004-2012 }\end{array}$} & \multirow{3}{*}{$\begin{array}{c}\text { (5) } \\
\text { Under } 16\end{array}$} & \multirow{2}{*}{ (6) } \\
\hline & & & & & & \\
\hline & 2004-2012 & 2004-2007 & 2008-2012 & & & 2008-2012 \\
\hline \multirow[t]{2}{*}{ LARC } & -0.059 & -0.328 & 0.031 & -0.011 & 0.008 & 0.004 \\
\hline & $(0.063)$ & $(0.259)$ & $(0.043)$ & $(0.011)$ & $(0.025)$ & $(0.014)$ \\
\hline \multirow[t]{2}{*}{ GPLARC } & & & 0.048 & & & $0.039^{*}$ \\
\hline & & & $(0.088)$ & & & $(0.021)$ \\
\hline \multirow[t]{2}{*}{ GCSE } & $-0.677^{* * *}$ & -0.385 & $-0.556^{* * *}$ & $-0.065^{* *}$ & -0.023 & $-0.117^{* * *}$ \\
\hline & $(0.121)$ & $(0.259)$ & $(0.186)$ & $(0.026)$ & $(0.047)$ & $(0.037)$ \\
\hline \multirow[t]{2}{*}{ Non-white pop } & $-0.583^{* *}$ & $-1.695^{* * * *}$ & -0.314 & -0.043 & -0.065 & 0.008 \\
\hline & $(0.259)$ & $(0.585)$ & $(0.301)$ & $(0.045)$ & $(0.095)$ & $(0.067)$ \\
\hline \multirow[t]{2}{*}{ LARC neighbour } & -0.102 & 0.182 & $-0.163^{*}$ & -0.003 & 0.037 & -0.023 \\
\hline & $(0.090)$ & $(0.190)$ & $(0.091)$ & $(0.020)$ & $(0.092)$ & $(0.021)$ \\
\hline \multirow[t]{2}{*}{ Pharmacy } & -1.049 & -1.297 & -0.484 & 0.294 & 0.259 & -0.347 \\
\hline & $(1.191)$ & $(1.371)$ & $(2.073)$ & $(0.245)$ & $(0.297)$ & $(0.503)$ \\
\hline \multirow[t]{2}{*}{ Clinic } & & -0.015 & & & 0.005 & \\
\hline & & $(0.012)$ & & & $(0.004)$ & \\
\hline \multirow[t]{2}{*}{ Unem } & $5.311^{* * *}$ & 2.448 & -1.067 & $1.174^{* * *}$ & 0.710 & 0.241 \\
\hline & $(1.741)$ & (2.088) & $(2.126)$ & $(0.444)$ & $(0.649)$ & $(0.438)$ \\
\hline \multirow[t]{2}{*}{ Care } & 0.058 & -0.103 & $0.314^{*}$ & 0.038 & 0.039 & 0.005 \\
\hline & $(0.134)$ & $(0.170)$ & $(0.176)$ & $(0.032)$ & $(0.065)$ & $(0.046)$ \\
\hline \multirow[t]{2}{*}{ Alcohol } & & & 0.399 & & & -0.273 \\
\hline & & & $(0.616)$ & & & $(0.187)$ \\
\hline $\mathbf{N}$ & 871 & 388 & 483 & 871 & 388 & 483 \\
\hline Adjusted R2 & 0.898 & 0.911 & 0.921 & 0.805 & 0.818 & 0.810 \\
\hline Mean Dep Vble & 46.79 & 52.71 & 42.05 & 7.445 & 8.145 & 6.883 \\
\hline
\end{tabular}

(i) See Table 2 notes (i)-(iv)

(ii) Dependent variables are in rates per thousand women aged 16-17 and 13-15 respectively.

(iii) GCSE is defined as the three-year running average for 16-17s but the current value for under-16s. 
Table 5: Robustness checks 3 - various specifications for U18 conceptions, 2004-2012

\begin{tabular}{|c|c|c|c|c|c|c|c|c|}
\hline & \multirow{2}{*}{\multicolumn{2}{|c|}{$\frac{(1)}{\text { w/o London }}$}} & \multicolumn{2}{|c|}{ (3) } & \multicolumn{2}{|c|}{ (5) } & \multicolumn{2}{|c|}{ (7) } \\
\hline & & & \multicolumn{2}{|c|}{ area specific trends } & \multicolumn{2}{|c|}{ pre-treatment trend } & \multicolumn{2}{|c|}{ LARC in rates } \\
\hline & 2004-2007 & $2008-2012$ & 2004-2007 & 2008-2012 & 2004-2007 & 2008-2012 & 2004-2007 & 2008-2012 \\
\hline \multirow[t]{2}{*}{ LARC } & -0.303 & 0.030 & -0.301 & -0.021 & -0.304 & 0.017 & -0.086 & $-0.021^{*}$ \\
\hline & $(0.236)$ & $(0.039)$ & $(0.336)$ & $(0.036)$ & $(0.209)$ & $(0.037)$ & $(0.073)$ & $(0.011)$ \\
\hline \multirow[t]{2}{*}{ GPLARC } & & -0.014 & & -0.023 & & 0.046 & & 0.022 \\
\hline & & $(0.075)$ & & $(0.089)$ & & $(0.065)$ & & $(0.064)$ \\
\hline \multirow[t]{2}{*}{ GCSE } & -0.226 & $-0.511^{* * *}$ & -0.259 & -0.440 & $-0.387^{*}$ & $-0.504 * * *$ & $-0.386^{* *}$ & $-0.446^{* * *}$ \\
\hline & $(0.207)$ & $(0.151)$ & $(0.630)$ & $(0.294)$ & $(0.096)$ & $(0.132)$ & $(0.180)$ & $(0.134)$ \\
\hline \multirow[t]{2}{*}{ Non-white } & $-1.276^{* *}$ & -0.355 & $-2.710^{* *}$ & -1.370 & $-1.262 * * *$ & -0.102 & $-1.267^{* * *}$ & -0.171 \\
\hline & $(0.540)$ & $(0.303)$ & $(1.236)$ & $(0.936)$ & $(0.481)$ & $(0.255)$ & $(0.457)$ & $(0.249)$ \\
\hline \multirow[t]{2}{*}{ LARC neighbour } & 0.227 & $-0.138^{*}$ & 0.515 & -0.077 & 0.302 & $-0.126^{*}$ & $0.152^{* *}$ & $-0.071^{* *}$ \\
\hline & $(0.246)$ & $(0.076)$ & $(0.430)$ & $(0.079)$ & $(0.225)$ & $(0.073)$ & $(0.070)$ & $(0.032)$ \\
\hline \multirow[t]{2}{*}{ Pharmacy } & -0.697 & $-2.523^{*}$ & -0.587 & $-4.265^{*}$ & -0.570 & -0.699 & -0.626 & -0.777 \\
\hline & $(0.965)$ & (1.331) & (1.660) & $(2.312)$ & $(0.905)$ & (1.601) & $(0.851)$ & (1.590) \\
\hline \multirow[t]{2}{*}{ Clinic } & -0.004 & & 0.015 & & -0.013 & & -0.002 & \\
\hline & $(0.012)$ & & $(0.023)$ & & $(0.014)$ & & $(0.011)$ & \\
\hline \multirow[t]{2}{*}{ Unem } & 1.201 & -1.593 & 0.477 & -0.686 & $2.712 *$ & -1.053 & 2.386 & -0.482 \\
\hline & $(1.885)$ & (1.554) & $(2.286)$ & (1.838) & (1.611) & $(1.417)$ & $(1.524)$ & (1.327) \\
\hline \multirow[t]{2}{*}{ Care } & -0.265 & 0.170 & $-0.448^{*}$ & 0.078 & -0.171 & $0.243 * *$ & -0.147 & $0.266^{* *}$ \\
\hline & $(0.233)$ & $(0.153)$ & $(0.226)$ & $(0.245)$ & $(0.129)$ & $(0.102)$ & $(0.124)$ & $(0.105)$ \\
\hline \multirow[t]{2}{*}{ Alcohol } & & 0.463 & & -0.246 & & 0.163 & & 0.076 \\
\hline & & $(0.521)$ & & $(0.886)$ & & $(0.523)$ & & $(0.516)$ \\
\hline \multirow[t]{2}{*}{ Pre-trend } & & & & & -0.016 & 0.059 & & \\
\hline & & & & & $(0.102)$ & $(0.107)$ & & \\
\hline $\mathbf{N}$ & 308 & 384 & 388 & 484 & 388 & 484 & 388 & 484 \\
\hline Adjusted $\mathbf{R}^{2}$ & 0.935 & 0.941 & 0.950 & 0.949 & 0.936 & 0.934 & 0.936 & 0.935 \\
\hline Mean Dep Vble & 43.84 & 36.12 & 43.24 & 35.04 & 43.24 & 35.04 & 43.24 & 35.04 \\
\hline
\end{tabular}

$\begin{array}{ll}24 & \text { Notes } \\ 25 & \text { (i) See Table } 2 \text { notes (i)-(iv) }\end{array}$


Table 6: Robustness checks 4- under-18 conceptions, births \& abortions, 2004-2012 with some interaction terms

\begin{tabular}{|c|c|c|c|c|c|c|c|c|c|}
\hline & (1) & $\begin{array}{c}(2) \\
2004-2012\end{array}$ & (3) & (4) & $\begin{array}{c}(5) \\
2004-2007\end{array}$ & (6) & (7) & $\begin{array}{c}(8) \\
2008-2012\end{array}$ & (9) \\
\hline & Conceptions & Abortions & Births & Conceptions & Abortions & Births & Conceptions & Abortions & Births \\
\hline \multirow[t]{2}{*}{ LARC } & $-0.130^{*}$ & -0.036 & $-0.095^{* * *}$ & -0.155 & -0.092 & -0.063 & -0.050 & -0.017 & -0.033 \\
\hline & $(0.066)$ & $(0.036)$ & $(0.035)$ & $(0.247)$ & $(0.143)$ & $(0.140)$ & $(0.045)$ & $(0.029)$ & $(0.041)$ \\
\hline \multirow[t]{2}{*}{ LARC* GCSE } & $0.007^{*}$ & 0.003 & $0.005^{* *}$ & 0.014 & 0.005 & 0.009 & $0.006^{*}$ & $0.005^{* *}$ & 0.001 \\
\hline & $(0.004)$ & $(0.002)$ & $(0.002)$ & $(0.016)$ & $(0.013)$ & $(0.008)$ & $(0.004)$ & $(0.002)$ & $(0.003)$ \\
\hline \multirow[t]{2}{*}{ LARC *Non-white } & -0.001 & -0.002 & 0.001 & -0.000 & -0.001 & 0.000 & -0.001 & -0.002 & 0.001 \\
\hline & $(0.003)$ & $(0.002)$ & $(0.001)$ & $(0.006)$ & $(0.005)$ & $(0.004)$ & $(0.002)$ & $(0.001)$ & $(0.001)$ \\
\hline \multirow[t]{2}{*}{ GPLARC } & & & & & & & 0.038 & 0.013 & 0.025 \\
\hline & & & & & & & $(0.059)$ & $(0.041)$ & $(0.039)$ \\
\hline \multirow[t]{2}{*}{ GCSE } & $-0.592^{* * *}$ & $-0.185^{* * *}$ & $-0.407^{* * *}$ & $-0.463^{* *}$ & -0.059 & $-0.404^{* * *}$ & $-0.606^{* * *}$ & $-0.359^{* * *}$ & $-0.247^{* * *}$ \\
\hline & $(0.108)$ & $(0.067)$ & $(0.062)$ & $(0.204)$ & $(0.150)$ & $(0.118)$ & $(0.142)$ & $(0.098)$ & $(0.078)$ \\
\hline \multirow[t]{2}{*}{ Non-white pop } & -0.320 & -0.097 & -0.223 & $-1.212^{* *}$ & -0.433 & $-0.779^{* *}$ & 0.058 & 0.202 & -0.144 \\
\hline & $(0.233)$ & $(0.139)$ & $(0.168)$ & $(0.474)$ & $(0.348)$ & $(0.343)$ & $(0.269)$ & $(0.197)$ & $(0.216)$ \\
\hline \multirow[t]{2}{*}{ LARC neighbour } & -0.070 & -0.019 & -0.051 & 0.267 & 0.197 & 0.070 & $-0.141^{*}$ & $-0.078^{*}$ & -0.063 \\
\hline & $(0.070)$ & $(0.039)$ & $(0.049)$ & $(0.233)$ & $(0.148)$ & $(0.153)$ & $(0.071)$ & $(0.044)$ & $(0.048)$ \\
\hline \multirow[t]{2}{*}{ Pharmacy } & -0.306 & -0.241 & -0.065 & -0.486 & -0.527 & 0.042 & -0.572 & 0.128 & -0.700 \\
\hline & $(0.858)$ & $(0.505)$ & $(0.582)$ & $(0.911)$ & $(0.626)$ & $(0.657)$ & (1.590) & $(0.871)$ & (1.144) \\
\hline \multirow[t]{2}{*}{ Clinic } & & & & -0.010 & -0.007 & -0.004 & & & \\
\hline & & & & $(0.012)$ & $(0.009)$ & $(0.008)$ & & & \\
\hline \multirow[t]{2}{*}{ Unem } & $4.115^{* * *}$ & $3.229^{* * *}$ & 0.887 & 2.535 & $2.260^{*}$ & 0.275 & -1.265 & -0.763 & -0.502 \\
\hline & $(1.539)$ & $(1.026)$ & $(0.684)$ & $(1.536)$ & (1.259) & $(0.985)$ & $(1.396)$ & $(0.952)$ & $(0.751)$ \\
\hline \multirow[t]{2}{*}{ Care } & 0.035 & 0.060 & -0.025 & -0.164 & -0.089 & -0.075 & $0.219^{* *}$ & $0.140^{* *}$ & 0.078 \\
\hline & $(0.099)$ & $(0.070)$ & $(0.051)$ & $(0.127)$ & $(0.100)$ & $(0.086)$ & $(0.100)$ & $(0.054)$ & $(0.064)$ \\
\hline \multirow[t]{2}{*}{ Alcohol } & & & & & & & 0.242 & 0.072 & 0.170 \\
\hline & & & & & & & $(0.511)$ & $(0.304)$ & $(0.340)$ \\
\hline $\mathbf{N}$ & 872 & 872 & 872 & 388 & 388 & 388 & 484 & 484 & 484 \\
\hline Adjusted $\mathbf{R}^{2}$ & 0.915 & 0.842 & 0.922 & 0.936 & 0.876 & 0.941 & 0.935 & 0.864 & 0.935 \\
\hline Mean Dep Vble & 38.69 & 18.76 & 19.93 & 43.24 & 20.66 & 22.58 & 35.04 & 17.23 & 17.80 \\
\hline
\end{tabular}

$\begin{array}{ll}28 & \text { Notes } \\ 29 & \text { (i) See Table } 2 \text { notes (i)-(iv) }\end{array}$


Table A1: Variable definition and sources

\section{Appendix}

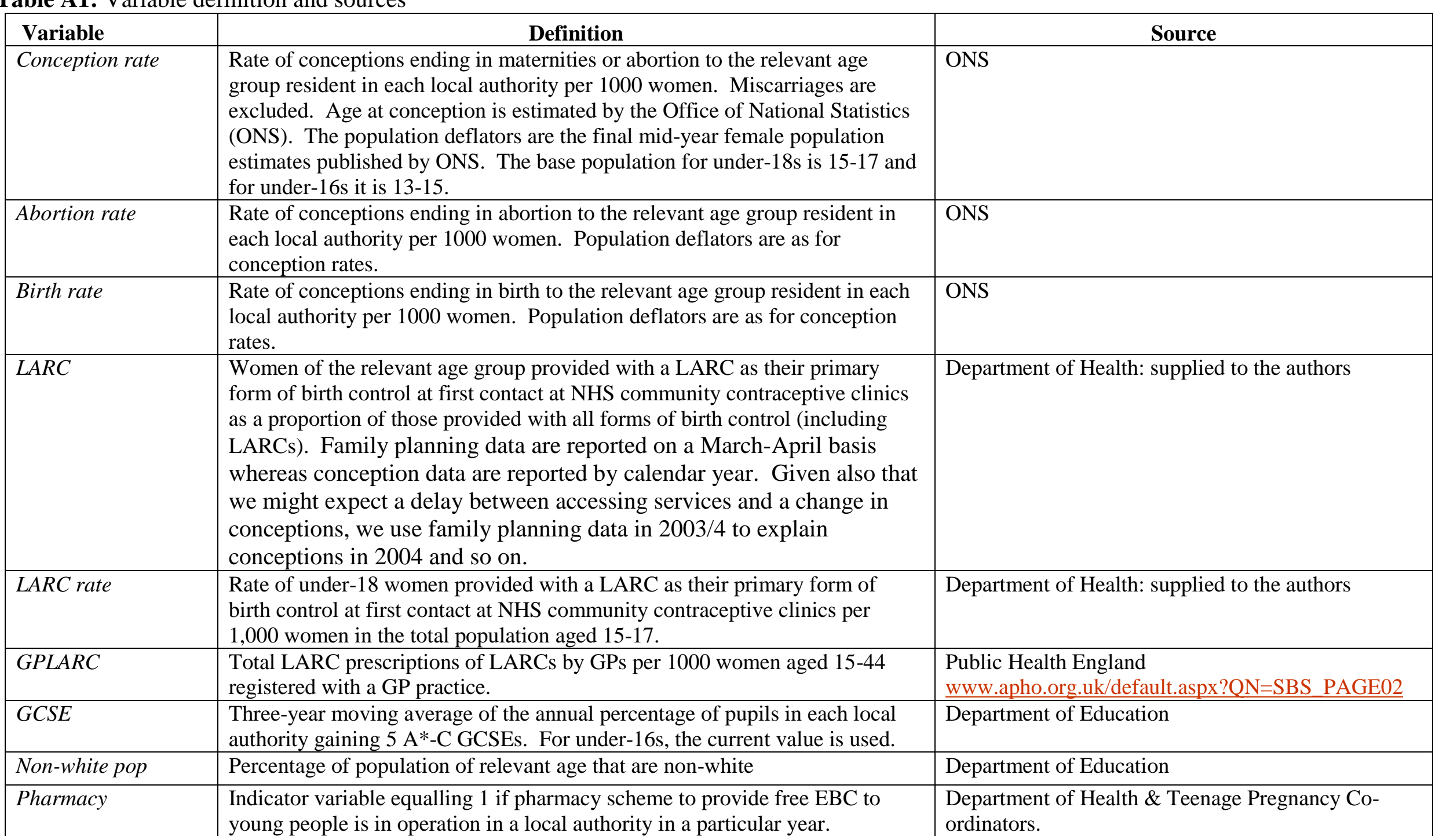




\begin{tabular}{|l|l|l|}
\hline Clinic & $\begin{array}{l}\text { Annual number of family planning clinic sessions aimed at young people per } \\
1,000 \text { females of the relevant age group. }\end{array}$ & Department of Health: supplied to the authors \\
\hline Unem & Annual \% unemployment rate for women aged under 20. & ONS: www.nomisweb.co.uk/ \\
\hline Care & $\begin{array}{l}\text { Rate of all children aged 15-17 under local authority care per 10,000. For 16- } \\
17 \text { s and U16s, the rates are calculated for children aged 16-17 and 10-15 } \\
\text { respectively. }\end{array}$ & Department of Health \\
\hline Alcohol & $\begin{array}{l}\text { Rate of under-18s admitted to hospital with alcohol-specific conditions per } \\
100,000 \text { population. }\end{array}$ & Public Health England. \\
\hline
\end{tabular}

